\title{
Predictive Growth Modeling of Listeria monocytogenes in Rice Balls and Its Risk Assessment
}

\author{
Seoungsoon Yeo and Misook Kim \\ Department of Food Science and Nutrition, Dankook University, Cheonan, Republic of Korea \\ Correspondence should be addressed to Misook Kim; mkim5@dankook.ac.kr
}

Received 21 March 2020; Revised 20 August 2020; Accepted 28 August 2020; Published 10 September 2020

Academic Editor: Elena Gonz lez Fandos

Copyright (c) 2020 Seoungsoon Yeo and Misook Kim. This is an open access article distributed under the Creative Commons Attribution License, which permits unrestricted use, distribution, and reproduction in any medium, provided the original work is properly cited.

\begin{abstract}
This study aimed to investigate the growth of Listeria monocytogenes in rice balls and to conduct its microbial risk assessment based on the Korean dietary pattern. Each tuna or ham rice ball was mixed with mayonnaise, soy sauce, or gochujang, a Korean traditional fermented red peeper paste, which was artificially contaminated with $L$. monocytogenes and then stored at $7^{\circ} \mathrm{C}-25^{\circ} \mathrm{C}$ to assess bacterial growth. Growth data were analyzed using three primary models (the Huang, Baranyi, and Gompertz models), and the growth pattern was found to fit well to the Baranyi model based on the following five statistical criteria: root mean square error (0.38-0.56), Akaike's information criterion (-51.55--26.99), coefficient of determination (0.72-0.97), bias factor (0.97-1.01), and accuracy factor (1.06-1.18). The effects of temperature on bacterial growth rate and lag time were evaluated using the square root model. The minimum growth temperature for L. monocytogenes in tuna or ham rice balls was the lowest when they were mixed with mayonnaise $\left(-9.44^{\circ} \mathrm{C}\right.$ or $-15.37^{\circ} \mathrm{C}$, respectively). Risk assessment using FDA-iRISK showed that tuna or ham rice balls mixed with gochujang exhibited the highest microbial risk among all the rice balls tested, regardless of the storage temperature. Tuna or ham rice balls mixed with gochujang had the highest disability-adjusted life years per year (0.015) followed by ham rice balls mixed with soy sauce $(0.011-0.015)$ or mayonnaise $(0.006-0.015)$ and then tuna rice balls mixed with soy sauce $(0.006-0.008)$ or mayonnaise $(<0.001)$. In conclusion, our results, determined using predictive growth models, allow the assessment of potential risk ranking associated with the consumption of rice balls contaminated with L. monocytogenes based on the number of illnesses experienced per serving and the disease burden.
\end{abstract}

\section{Introduction}

Listeria monocytogenes is widely distributed in the natural environment, grows at a wide range of temperatures from $0^{\circ} \mathrm{C}$ to $45^{\circ} \mathrm{C}$, and is resistant to a variety of environmental conditions such as high salinity $(10 \%-12 \% \mathrm{NaCl})$ [1], low water activity (minimum 0.83 ) [2], and low $\mathrm{pH}$ (minimum 4.4) [3]. According to the Centers for Disease Control and Prevention, L. monocytogenes is accountable for approximately 1,591 cases of listeriosis, 1,455 hospitalizations, and 255 deaths annually in the United States [4]. In general, compared with healthy individuals, the risk of fatal invasive listeriosis is high in vulnerable populations, including pregnant women, newborns, elderly, and immunocompromised patients, resulting in a death rate of $20 \%-30 \%$
$[5,6]$. Reportedly, listeriosis is primarily associated with the consumption of refrigerated ready-to-eat (RTE) foods as these foods are not pasteurized $[5,7]$. Thus, controlling the contamination of RTE foods with L. monocytogenes is crucial in the food industry.

In Korea, rice balls and kimbab are popular convenience foods and are consumed at a high rate of $54.4 \%$ among convenience food consumption as a substitute for meals $[8,9]$. Both are made by combining cooked rice with side ingredients such as ham, tuna, meat, cheese, or vegetables. However, these are distinguished in their shape and the number of side ingredients. Korean rice balls are made from rice and fillings such as a few minced ingredients mixed with dressings formed into oval or triangular shapes. Kimbab is a seaweed rice roll containing several ingredients. According to the Institute of Food 
Technology [10], convenience foods such as rice balls, kimbab, and sushi that contain cooked rice and various other ingredients are considered potentially hazardous foods and require control of storage time and temperature during their shelf-life. Such foods have been reported to cause many cases of foodborne diseases linked to enteric bacteria in Korea [11]. Foodborne bacteria were detected in 21 out of 77 commercial kimbab as a result of hygiene inspection of convenience foods [12]. There are no reported cases on foodborne disease caused from L. monocytogenes in rice balls and kimbab in Korea. However, its outbreak possibility is high due to the rapid growth of HMR (home meal replacement) and CMR (convenient meal replacement) markets.

Several researchers have developed predictive growth models and quantitative microbial risk assessments (QMRAs) for Staphylococcus aureus in kimbab $[13,14]$. L. monocytogenes is another significant pathogen present in refrigerated convenience foods such as kimbab, rice balls, and sushi owing to its ability to grow at low temperatures; however, risk assessment studies on this pathogen have been relatively limited. Rice balls, which contain a single main ingredient (usually tuna, ham, or sauce) other than rice, slightly differ from kimbab, which contains a number of ingredients. In Japan, the contamination risk of RTE foods containing raw minced tuna as a main ingredient with L. monocytogenes was 5.7\%-12.1\% [15]; moreover, a survey revealed that the contamination risk of sausages and ham with L. monocytogenes was ranked in top 10 on the necessity of priority management targeting Korean livestock coops [16]. Thus, in this study, the risk of L. monocytogenes was assessed in tuna or ham rice balls containing one of three popular sauces (mayonnaise, soy sauce, or gochujang) each as the main ingredient.

Predictive growth models are mathematical expressions that can analyze and predict the growth and survival of microorganisms for assessing food safety [17]. They can be useful in decision-making with respect to critical control points (CCP) in hazard analysis and CCP (HACCP) systems and microbial risk assessment for preventing foodborne illnesses and food spoilage [18]. The growth pattern of $L$. monocytogenes in foods is dependent on nutrients, water activity, $\mathrm{pH}$, the presence of antagonists and synergists, redox potentials in the food matrix, and the environment in which food is stored [19]. The Integrated Pathogen Modeling Program, 2013 (IPMP, 2013) of the United States Department of Agriculture used in this study is one of several predictive software tools that models the growth of microorganisms. QMRA is a scientific method for assessing the risk of foodborne illness after the consumption of foods contaminated with certain pathogenic microorganisms $[10,20]$. It includes four steps: hazard identification, exposure assessment, hazard characterization, and risk characterization. Therefore, QMRA can provide food safety standards for foodborne pathogenic microorganisms by estimating the risk of illness due to a certain pathogen in a certain population.

Food and Drug Administration- (FDA-) iRISK, which was developed by the US FDA, is an interactive, web-based, comparative risk assessment tool. It can calculate and determine risk ranks using mathematical logic and Monte Carlo simulations and using data on the number of diseases and then translate the result into public health metrics that facilitate the comparisons of public health burdens [21]. In this study, we used predictive modeling to investigate the growth characteristics of L. monocytogenes in various types of rice balls stored at different temperatures, and the predicted growth parameters obtained from a suitable model were used in risk assessment. QMRA of L. monocytogenes in various rice balls was then conducted using FDA-iRISK to compare, evaluate, and rank risk depending on different environmental conditions.

\section{Materials and Methods}

2.1. Preparation of Rice Balls. Salad mixtures of tuna or ham were first prepared by mixing canned minced tuna (Dongwon F\&B Co., Ltd., Changwon, Korea) with mayonnaise (Ottogi, Eumseong, Korea), soy sauce (Sempio, Incheon, Korea), or gochujang (CJ Cheiljedang Co., Ltd., Nonsan, Korea) in the ratios of $3: 1,15: 1$, or $10: 1$, respectively, or cubed ham (1 cm pieces; CJ Cheiljedang Co., Ltd., Seoul, Korea) with the same sauces in the ratios (weight: weight) of $5: 1,12: 1$, or $12: 1$, respectively. The bacterial cell number of initial rice balls was $2.26 \mathrm{log} \mathrm{CFU} / \mathrm{g}$ before inoculation of L. monocytogenes. An overnight culture of L. monocytogenes (KCTC 3710) was inoculated into each salad mixture at approximately $3 \mathrm{log}$ CFU/gram of rice balls. Each salad mixture was wrapped with cooked rice (Chucheong variety, Nonghyup, Anseong, Korea; ratio, $1: 4$ ), and each ball was sealed in a sterile plastic bag and stored at $7^{\circ} \mathrm{C}, 15^{\circ} \mathrm{C}$, or $25^{\circ} \mathrm{C}$. L. monocytogenes was enumerated at each sampling time point by incubation on TSA (BD Difco, Sparks, MD) at $37^{\circ} \mathrm{C}$ for $24 \mathrm{~h}$. All microbial analyses were conducted for each rice ball in four repetitions.

2.2. Primary Model. The growth rate $\left(\mu_{\max }\right.$ and specific growth rate (SGR); log CFU/h) and lag time (LT; h) of $L$. monocytogenes were determined using three primary models (the Huang, Baranyi, and Gompertz models) using IPMP (IPMP, 2013) software.

The Huang model is described by the following equation:

$$
\begin{aligned}
& Y(t)=Y_{0}+Y_{\max }-\ln \left\{e^{Y_{0}}+\left[e^{Y_{\max }}-e^{Y_{0}}\right] e^{-\mu \max ^{B(t)}},\right. \\
& B(t)=t+\frac{1}{4} \ln \frac{1+e^{-4(t-\lambda)}}{1+e^{4 \lambda}},
\end{aligned}
$$

where $Y_{0}, Y_{\max }$, and $Y(t)$ are the natural logarithms of the initial bacterial population count, maximum count, and the count at time $t$, respectively; $\mu_{\max }$ is the maximum SGR; and $\lambda$ is the lag-phase duration.

The Baranyi model is described by the following equation:

$$
\begin{aligned}
& Y(t)=Y_{0}+\mu_{\max } A(t)-\ln \left\{1+\frac{\exp \left[\mu_{\max } A(t)\right]-1}{\exp \left(Y_{\max }-Y_{0}\right)}\right\}, \\
& A(t)=t+\frac{1}{\mu_{\max }} \ln \left[\exp \left(-\mu_{\max } t\right)+\exp \left(-h_{0}\right)-\exp \left(-\mu_{\max } t-h_{0}\right)\right],
\end{aligned}
$$


where $Y_{0}, Y_{\max }, Y(t)$, and $\mu_{\max }$ represent the same quantities as those in equation (1) and $h_{0}$ is the physiological state of the microorganism under consideration. In the Baranyi model, the lag phase corresponds to $h_{0} / \mu_{\max }$, and $h_{0}$ can be different and unique for each curve. In the Baranyi model, the initial growth curves observed at constant temperature conditions were analyzed to obtain each $h_{0}$ value. After analyzing all the growth curves, the $h_{0}$ values were averaged to produce a global value. All growth curves were then reanalyzed using the average value of $h_{0}$ to determine $\mu_{\max }$ at each incubation temperature.

The Gompertz model is described by the following equation:

$$
Y(t)=Y_{0}+\left(Y_{\max }-Y_{0}\right) \exp \left\{-\exp \left[\frac{\mu_{\max } e}{Y_{\max }-Y_{0}}(\lambda-t)+1\right]\right\},
$$

where $Y_{0}, Y_{\max }, Y(t), \mu_{\max }$, and $\lambda$ represent the same quantities as those in equation (1).

2.3. Secondary Model. Temperature-dependent variations in the maximum SGR and LT were analyzed using square root and polynomial models, respectively, using Microsoft Excel 2016 (Microsoft Corp, Redmond, Washington). The equations used are shown in equations (4) to (6):

$$
\begin{gathered}
\ln (S G R): a+b T+c T^{2}, \\
\ln (L T): a+b T+c T^{2}, \\
T_{\min }: \sqrt{\mu_{\max }}=a\left(T-T_{\min }\right),
\end{gathered}
$$

where SGR is in $\log \mathrm{CFU} / \mathrm{h}$ and LT is in hours. $T$ is the temperature ( $\underline{\mathrm{o}} \mathrm{C}) ; T_{\min }$ is the intercept between the slope and the temperature axis; and $a, b$, and $c$ are regression constants.

2.4. Model Validation. Model acceptability for L. monocytogenes in rice balls was evaluated based on the root mean square error (RMSE), coefficient of determination $\left(R^{2}\right)$, Akaike's information criterion (AIC), bias factor, and accuracy factor.

RMSE is the difference between observed and predicted data. For RMSE, values close to zero are desirable as they indicate that the predicted values are very close to the observed values.

$R^{2}$ is calculated using the following equation:

$$
R^{2}=1-\left[\frac{\sum e_{i}^{2}}{\sum\left(y_{i}-y^{\prime}\right)^{2}}\right],
$$

where $e_{i}$ is the error of the predictive value, $y_{i}$ is the predictive data, and $y$ is the average of predictive data.

AIC is calculated using the following equation:

$$
A I C_{c}=-2 \ln (\text { likelihood })+2 K+\frac{2 K(K+1)}{n-K-1},
$$

where $n$ is the number of observations and $K$ is the number of parameters in the model. $B_{f}$ and $A_{f}$ were calculated using equations (9) and (10), respectively:

$$
\begin{gathered}
B_{f}=10\left\{\left(\sum \log (\text { pred/obs })\right) / n\right\}, \\
A_{f}=10\left\{\sum \mid \log (\text { pred/obs }) \mid / n\right\},
\end{gathered}
$$

where obs, pred, and $n$ correspond to the observed value, predicted value, and repetition number of the observed data, respectively. Values near to 1 indicate the suitability of the model, whereas the values $<0.7$ or $>1.5$ indicate the unsuitability of the model.

2.5. Risk Assessment for Rice Balls Using FDA-iRISK. Results of risk assessment of all tested rice balls were compared using FDA-iRISK (version 4.0, FDA, US).

\section{Results and Discussion}

3.1. Growth of L. monocytogenes in Tuna or Ham Rice Balls Mixed with Three Sauces. The initial number of L. monocytogenes cells in all rice balls was approximately $3.60 \pm 0.36$ $\log \mathrm{CFU} / g$; growth curves of $L$. monocytogenes in six rice balls at different storage temperatures are shown in Figure 1. Bacterial growth in the food matrix is dependent on several factors such as the presence of other microbiota, nutrients, $\mathrm{pH}$, temperature, and water activity $[22,23]$. Lower temperatures retarded bacterial growth in all rice balls. Distinctly different growth pattern in LTM (tuna rice balls mixed with mayonnaise; Figure $1(\mathrm{a})$ ) at $7^{\circ} \mathrm{C}$ from other samples was observed. Mixing mayonnaise negatively affected bacterial growth in both tuna and ham rice balls. The growth rate of L. monocytogenes in LTM was slower than that in other samples, and its maximal growth did not exceed $6.5 \log \mathrm{CFU} / \mathrm{g}$. Additionally, mixing mayonnaise in ham rice balls resulted in the lowest maximum growth $(<7 \log \mathrm{CFU} / \mathrm{g})$ of LHM (ham rice balls mixed with mayonnaise). The low growth in mayonnaise may be due to the presence of eggderived antibacterial substances such as lysozyme and ovotransferrin, although these are present at very low levels $[24,25]$. In general, L. monocytogenes had a higher growth rate in ham rice balls than in tuna. The maximum population of L. monocytogenes at $25^{\circ} \mathrm{C}$ was $4.5 \mathrm{log} \mathrm{CFU} / \mathrm{g}$ in LTM, 6.88 $\log \mathrm{CFU} / \mathrm{g}$ in LTS, $7.38 \mathrm{log} \mathrm{CFU} / \mathrm{g}$ in LTG, 6.84 log CFU/g in LHM, $8.00 \log \mathrm{CFU} / \mathrm{g}$ in LHS, and $8.18 \mathrm{log} \mathrm{CFU} / \mathrm{g}$ in LHG. The $\mathrm{pH}$ values of all rice balls decreased (from 5.38 to 5.12 in LTM; from 5.40 to 5.09 in LTS; from 5.45 to 5.07 in LTG; from 5.63 to 5.52 in LHM; from 5.55 to 5.47 in LHS; and from 5.67 to 5.59 in LHG) during storage at $7^{\circ} \mathrm{C}$ for $137 \mathrm{~h} . \mathrm{pH}$ of tuna rice balls was lower than ham rice balls.

3.2. Primary Modeling of L. monocytogenes Growth in Rice Balls. Many researchers agree that no single growth model can produce a consistent goodness of fit for all 


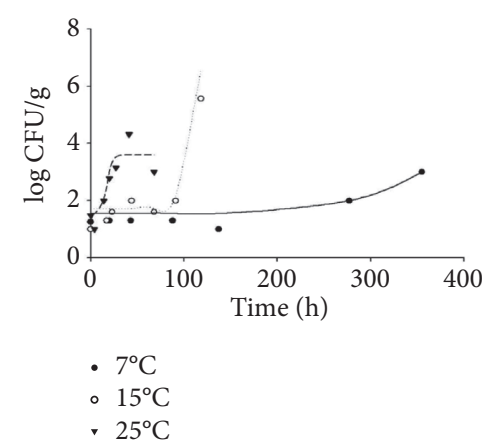

(a)

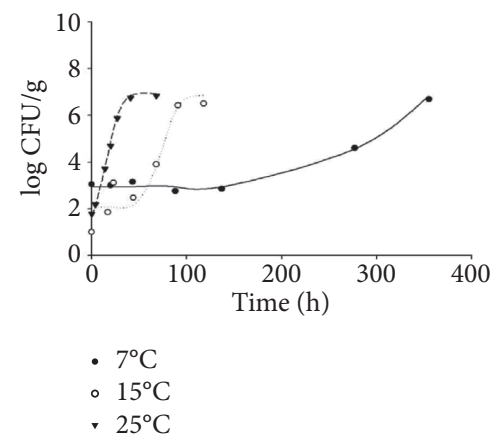

(d)

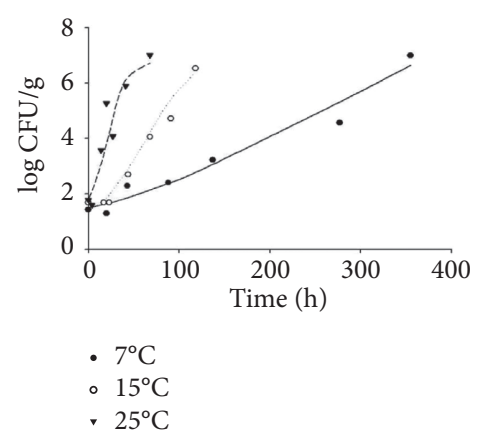

(b)

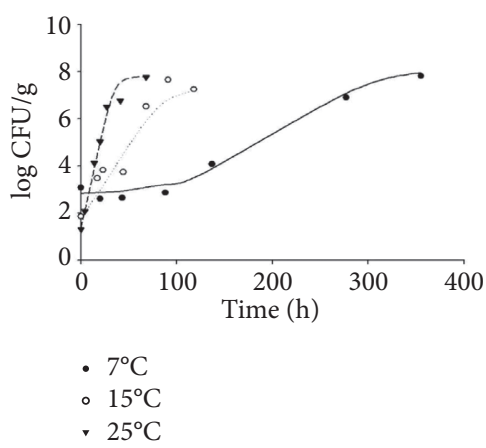

(e)

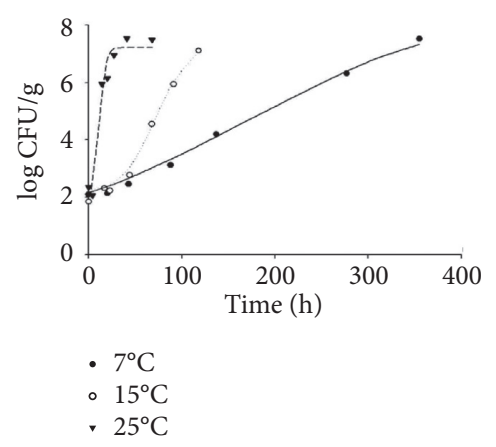

(c)

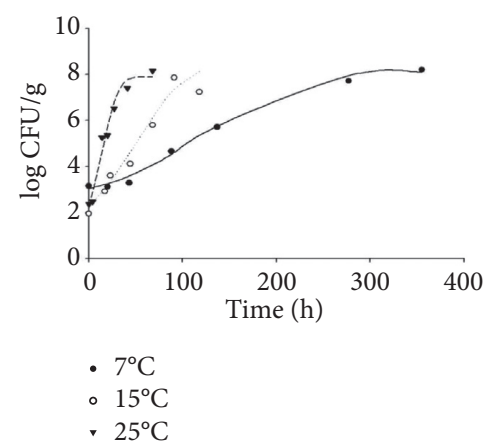

(f)

FIGURE 1: Growth of L. monocytogenes in rice balls by fitting the Baranyi model: tuna rice balls mixed with mayonnaise (a), soy sauce (b), and gochujang (c) and ham rice balls mixed with mayonnaise (d), soy sauce (e), and gochujang (f). Symbols, experimental data; line, fitted model.

experimental data [26-29]; therefore, most data are assessed using several primary models such as Gompertz, Baranyi, and Huang models (Supplementary Table 1). The microbial growth models such as Gompertz, Baranyi, and Huang models are basically similar. These have been used to calculate microbial growth parameters including lag time, specific growth rate, and maximum population density to estimate the microbial growth in food [29-31]. The results for microbial growth parameters are dependent on which primary model is employed due to the differences of the equations produced from each primary model. The Gompertz model is an empirical equation, the Baranyi model is semitheoretical, and the Huang equation is a theoretical model developed. The results for growth parameters sometimes show that these models were not significantly different [31]. Therefore, they were equally capable of explaining microbial growth in food. In our study, statistical values including $R^{2}$, RMSE, and AIC from all the models were similar for the predictive growth of $L$. monocytogenes in rice balls. In general, the Baranyi model was a better model for predicting L. monocytogenes in rice balls than the other models as it exhibited the lowest RMSE and AIC and the highest $R^{2}$. However, the Huang model was suitable for LTS at $15^{\circ} \mathrm{C}$ and LHG at $7^{\circ} \mathrm{C}$, whereas the Gompertz model was acceptable for LTG at $25^{\circ} \mathrm{C}$ and LHG at $25^{\circ} \mathrm{C}$. Even in the same food matrix, the model suitability differed depending on temperature [27]. When compared with the average values for each temperature, the Baranyi model produced the smallest average values for RMSE,
MSE, and AIC and the largest $R^{2}$ in most rice balls except in those containing gochujang. LTG and LHG were most accurately modeled using the Gompertz model, but there was no significant difference between the three models. Therefore, we concluded that the Baranyi model was the best primary model for determining the growth of $L$. monocytogenes in rice balls at all temperatures, and so, this model was used to predict the growth pattern of L. monocytogenes in rice balls (Figure 1). The experimental observations coincided well with the predicted values, which also predicted the lag and exponential phases.

3.3. Secondary Models for L. monocytogenes and Validation. SGR and LT predicted by the Baranyi model were used in a polynomial equation to fit to secondary models. These models were developed to describe the effect of temperature on the SGR and LT, and these equations estimated the SGR and LT of L. monocytogenes as a function of temperature (Table 1). Based on SGRs and LTs obtained, mayonnaise was determined as the sauce that most interfered with the growth of L. monocytogenes followed by soy sauce and gochujang. As the storage temperature increased, SGR increased (0.02-0.08 at $7^{\circ} \mathrm{C}, 0.06-0.20$ at $15^{\circ} \mathrm{C}$, and $0.15-0.38$ at $\left.25^{\circ} \mathrm{C}\right)$. As storage temperature increased, LT decreased $\left(42.55-278.53 \mathrm{~h}\right.$ at $7^{\circ} \mathrm{C}$, $3.71-93.65 \mathrm{~h}$ at $15^{\circ} \mathrm{C}$, and $6.96-14.41 \mathrm{~h}$ at $25^{\circ} \mathrm{C}$ ) under most growth conditions. These data demonstrate that the growth of the microorganisms is dependent on storage temperature. A short LT was observed for the bacteria in rice balls mixed 
TABLE 1: Secondary models developed for the specific growth rate (SGR, log CFU/g/h) and lag time (LT, $\mathrm{h}$ ) of L. monocytogenes in rice balls and statistical validation factors calculated for Baranyi models.

\begin{tabular}{|c|c|c|c|c|c|c|}
\hline \multirow{2}{*}{ Code } & \multirow{2}{*}{ Equation } & \multirow{2}{*}{$R^{2}$} & \multirow{2}{*}{$T_{\min }\left({ }^{\circ} \mathrm{C}\right)$} & \multicolumn{3}{|c|}{ Storage temperature } \\
\hline & & & & $7^{\circ} \mathrm{C}$ & $15^{\circ} \mathrm{C}$ & $25^{\circ} \mathrm{C}$ \\
\hline \multirow{2}{*}{$\mathrm{LTM}^{1)}$} & $\mathrm{SGR}=-0.0109+0.0127 \times T+0.0001 \times \mathrm{T}^{2}$ & 0.99 & \multirow[t]{2}{*}{-9.43} & $0.08 \pm 0.004$ & $0.20 \pm 0.003$ & $0.36 \pm 0.02$ \\
\hline & $\mathrm{LT}=540.2198-43.118 \times T+0.8826 \times \mathrm{T}^{2}$ & 0.99 & & $278.53 \pm 15.34$ & $93.62 \pm 1.30$ & $14.41 \pm 0.59$ \\
\hline \multirow{2}{*}{ LTS } & $\mathrm{SGR}=-0.0155+0.0039 \times T+0.0001 \times \mathrm{T}^{2}$ & 0.97 & \multirow[t]{2}{*}{-3.02} & $0.02 \pm 0.00$ & $0.06 \pm 0.01$ & $0.15 \pm 0.02$ \\
\hline & $\mathrm{LT}=87.2021-5.5066 \times T+0.0133 \times \mathrm{T}^{2}$ & 0.99 & & $52.07 \pm 0.00$ & $21.63 \pm 3.56$ & $-6.96 \pm 0.75$ \\
\hline \multirow{2}{*}{ LTG } & $\mathrm{SGR}=0.0889-0.0189 \times T+0.0012 \times \mathrm{T}^{2}$ & 0.99 & \multirow[t]{2}{*}{2.67} & $0.02 \pm 0.002$ & $0.08 \pm 0.004$ & $0.38 \pm 0.01$ \\
\hline & $\mathrm{LT}=1.7491+6.3248 \times \mathrm{T}-0.24796 \times \mathrm{T}^{2}$ & 0.98 & & $30.75 \pm 3.77$ & $40.38 \pm 1.98$ & $4.91 \pm 0.14$ \\
\hline \multirow{2}{*}{ LHM } & $\mathrm{SGR}=-0.0721+0.0217 \times \mathrm{T}-0.0004 \times \mathrm{T}^{2}$ & 0.95 & \multirow[t]{2}{*}{-15.40} & $0.06 \pm 0.001$ & $0.16 \pm 0.008$ & $0.21 \pm 0.03$ \\
\hline & $\mathrm{LT}=530.4548-47.236 \times T+1.0475 \times \mathrm{T}^{2}$ & 0.95 & & $250.00 \pm 5.35$ & $58.05 \pm 2.68$ & $4.35 \pm 0.48$ \\
\hline \multirow{2}{*}{ LHS } & $\mathrm{SGR}=0.0325-0.0034 \times T+0.0004 \times \mathrm{T}^{2}$ & 0.98 & \multirow[t]{2}{*}{-3.34} & $0.03 \pm 0.001$ & $0.07 \pm 0.003$ & $0.19 \pm 0.01$ \\
\hline & $\mathrm{LT}=287.397-30.0968 \times T+0.7449 \times \mathrm{T}^{2}$ & 0.99 & & $115.06 \pm 5.14$ & $3.71 \pm 0.39$ & $0.55 \pm 0.04$ \\
\hline \multirow{2}{*}{ LHG } & $\mathrm{SGR}=0.0418-0.0049 \times T+0.0004 \times \mathrm{T}^{2}$ & 0.99 & \multirow[t]{2}{*}{-2.73} & $0.03 \pm 0.002$ & $0.07 \pm 0.006$ & $0.20 \pm 0.007$ \\
\hline & $\mathrm{LT}=87.4372-7.5618 \times T+0.1591 \times \mathrm{T}^{2}$ & 0.99 & & $42.55 \pm 2.53$ & $9.75 \pm 0.87$ & $-2.19 \pm 0.07$ \\
\hline
\end{tabular}

1) LTM, LTS, and LTG are tuna rice balls mixed with mayonnaise, soy sauce, and gochujang contaminated by L. monocytogenes; LHM, LHS, and LHG are ham rice balls mixed with mayonnaise, soy sauce, and gochujang contaminated by L. monocytogenes.

with gochujang, indicating easy growth. Temperature has been reported to be an important environmental variable affecting microbial growth [32,33].

$R^{2}$ was estimated to evaluate the secondary models; higher $R^{2}$ reflected more accurate model predictions. In the Baranyi model, which was the most accurate among the three primary models, $R^{2}$ for SGR and LT model equations was $>0.95$, indicating good fit. Various developed models have been shown to be capable of predicting the growth of L. monocytogenes under the certain conditions [34]. $T_{\min }$ is the minimum temperature that facilitates bacterial growth estimated by the traditional Ratkowsky square model; in this study, we identified slight differences in $T_{\min }$ between tuna and ham rice balls, with ham rice balls exhibiting a lower value than tuna rice balls. Particularly, tuna or ham rice balls mixed with mayonnaise exhibited the lowest $T_{\min }\left(-9.43^{\circ} \mathrm{C}\right.$ and $-15.40^{\circ} \mathrm{C}$, respectively) followed by those mixed with soy sauce and gochujang. $T_{\min }$ of $L$. monocytogenes in rice balls is much lower than other reports [34-37]. $T_{\min }$ of L. monocytogenes grown in culture media under optimal conditions was reported from $0.5^{\circ} \mathrm{C}$ to $5^{\circ} \mathrm{C}$ [38]. $T_{\min }$ for pathogenic bacteria is dependent on the food type owing to differences in nutrients, $\mathrm{pH}$, water activity, salt content, and the presence of antagonists or synergists. The growth of $L$. monocytogenes at low temperatures has also been reported by Devlieghere et al. [36] and Franz et al. [37], who showed that the bacterium can grow at $-4.6^{\circ} \mathrm{C}$ and $-3.54^{\circ} \mathrm{C}$ in green leafy vegetables and cooked ham substrates, respectively. $T_{\min }$ of L. monocytogenes is substantially lower than that of other pathogenic bacteria such as Staphylococcus aureus in kimbab $\left(2.5^{\circ} \mathrm{C}\right)$ [39] and $E$. coli in beef meat $\left(1.5^{\circ} \mathrm{C}\right.$ to $\left.4.7^{\circ} \mathrm{C}\right)[40]$.

3.4. Risk Assessment of Rice Balls Using FDA-iRISK. Table 2 presents the model inputs for risk scenarios of L. monocytogenes in rice balls. Due to the absence of the reference literature for rice balls, reports on kimbab were used for determining the initial prevalence of L. monocytogenes [41]; among the 30 kimbab samples from local markets in Korea, $83.3 \%$ samples were contaminated with pathogenic bacteria including $L$. monocytogenes (6.7\%). Therefore, 0.067 was used as the input data for the initial prevalence. The consumption model included grams per eating occasion and annual eating occasions for kimbab $[42,45]$. The initial unit mass was the average serving size of commercial rice balls sold in convenience stores. Data from the Baranyi model were included in FDA-iRISK during the process stage and were designated as "increased" in software. The dose-response model and disease burden were based on a study by Pouillot et al. [43] and Noordhout et al. [44]. The DALY (disability-adjusted life years) is one of the health impact metrics that integrates information on the severity and duration of illness to estimate disease burden [46, 47]. DALY is measured as the sum of years of life lost by premature mortality and years lived with disability. It considers both the probability of experiencing an illness, injury, or even death and the impact of the associated health effect. The WHO estimated that listeriosis resulted in 23,150 illness and 172,823 DALY worldwide in 2010 [48]. Thus, we calculated the DALY per case as 7.46 following DALY divided by illness and listeriosis cases.

Table 3 shows the predictions obtained from FDAiRISK, including total number of illnesses, mean risk of illness, and total DALY per year for L. monocytogenes in tuna or ham rice balls mixed with the three different sauces and stored at different temperatures. In this study, the risk of illness from $L$. monocytogenes in rice balls varied with the main ingredients (i.e., tuna, ham, and the type of sauces) and storage temperature. Their risk rates ranged from 0.000003 to 0.041 based on the mean risk of illness and from 0.00000093 to 0.015 based on the total DALY per year. The highest risk, regardless of the storage temperature, occurred when rice balls were mixed with gochujang. As the storage temperature decreased, the risk of illness from L. monocytogenes did not decrease. The risks from LHS and LHM were also highest at $7^{\circ} \mathrm{C}$. Despite the low storage temperature at $7^{\circ} \mathrm{C}$, the risk of $L$. monocytogenes from rice balls mixed with mayonnaise or soy sauce was higher than that at $25^{\circ} \mathrm{C}$. 
TABLE 2: Model inputs for food scenarios of L. monocytogenes in rice balls in FDA-iRISK 4.0.

\begin{tabular}{|c|c|c|c|}
\hline \multirow{2}{*}{$\begin{array}{l}\text { Element of risk } \\
\text { scenario }\end{array}$} & \multicolumn{3}{|c|}{ L. monocytogenes in rice balls } \\
\hline & Input parameter, iRISK template & Model input & Reference \\
\hline Food & Rice ball, tuna & Description & - \\
\hline \multirow[t]{5}{*}{ Hazard } & L. monocytogenes & Description & - \\
\hline & Initial prevalence & 0.067 & Cho et al. [41] \\
\hline & & $\begin{array}{c}\mathrm{LTM}^{1)} \text { : uniform }(1.23,1.91 / \\
1.50,1.91 / 1.11,1.62) \log \mathrm{CFU}^{2)}\end{array}$ & \\
\hline & & $\begin{array}{c}\text { LTS: uniform }(1.40,1.64 / 1.26,1.39 / \\
1.51,1.99) \log \text { CFU }\end{array}$ & \\
\hline & & LTG: uniform $(1.71,2.45 / 1.94,2.74 /$ & \\
\hline \multirow[t]{19}{*}{ Process model } & Initial concentration & $\begin{array}{l}\text { 2.07,2.14) } \log \text { CFU } \\
\text {. }\end{array}$ & Experiment \\
\hline & & 1.95,2.14/1.05,1.92) log CFU & \\
\hline & & LHS: uniform $(2.58,3.15 / 1.37,2.05 /$ & \\
\hline & & $0.87,1.20) \log \mathrm{CFU}$ & \\
\hline & & LHG: uniform $(2.58,3.15 /$ & \\
\hline & & 2.04,2.79/2.16,2.36) log CFU & \\
\hline & Initial unit mass & $150 \mathrm{~g}$ & Experiment \\
\hline & & LTM: uniform $(3.00,3.01 /$ & \\
\hline & & $5.95,6.03 / 3.31,4.69) \log \mathrm{CFU}^{3)}$ & \\
\hline & & $\begin{array}{c}\text { LTS: uniform }(7.01,7.02 / 6.32,8.17 / \\
6.29,7.08) \log \mathrm{CFU}\end{array}$ & \\
\hline & & LTG: uniform $(8.11,9.59 / 7.09,7.51 /$ & \\
\hline & Process stage 1 : storage at 7,15 , and & 7.13,7.32) $\log \mathrm{CFU}$ & Experiment \\
\hline & $25^{\circ} \mathrm{C}$, increase by growth & LHM: uniform $(6.70,6.98 /$ & Experiment \\
\hline & & 6.60,7.16/6.81,7.06) log CFU & \\
\hline & & LHS: uniform $(7.83,8.53 / 6.81,7.68 /$ & \\
\hline & & 7.31,8.26) $\log \mathrm{CFU}$ & \\
\hline & & LHG: uniform $(7.83,8.53 /$ & \\
\hline & & 7.61,9.98/7.77,7.98) log CFU & \\
\hline & Grams per eating occasion & $118.6 \mathrm{~g}$ & Shin et al. [42] \\
\hline \multirow{2}{*}{$\begin{array}{l}\text { Consumption } \\
\text { model }\end{array}$} & & & Korea Health Statistics: \\
\hline & Eating occasions per year & 23.99 & $\begin{array}{c}\text { Korea National Health and Nutrition } \\
\text { Examination Survey (2016) }\end{array}$ \\
\hline \multirow{3}{*}{$\begin{array}{l}\text { Dose-response } \\
\text { model }\end{array}$} & Healthy people & $7.90 E-12$ & \multirow{3}{*}{ Pouillot et al. [43] } \\
\hline & Pregnant women & $2.01 E-09$ & \\
\hline & Elderly (more than 65 years old) & $1.49 E-10$ & \\
\hline \multirow{2}{*}{ Disease burden } & Healthy people & 0.015 DALY per case & \multirow{2}{*}{ Noordhout et al. [44] } \\
\hline & Pregnant women and elderly & 12.91 DALY per case & \\
\hline
\end{tabular}

1) LTM, LTS, and LTG are tuna rice balls mixed with mayonnaise, soy sauce, and gochujang contaminated by L. monocytogenes; LHM, LHS, and LHG are ham rice balls mixed with mayonnaise, soy sauce, and gochujang contaminated by L. monocytogenes. 2) Input data for the initial concentration input: minimum and maximum concentrations at $7^{\circ} \mathrm{C} /$ minimum and maximum concentrations at $15^{\circ} \mathrm{C} /$ minimum and maximum concentrations at $\left.25^{\circ} \mathrm{C} .3\right)$ Process stage input: minimum and maximum concentrations at $7^{\circ} \mathrm{C} /$ minimum and maximum concentrations at $15^{\circ} \mathrm{C} /$ minimum and maximum concentrations at $25^{\circ} \mathrm{C}$.

Variations in the microbiota population within a rice ball at room temperature may explain the interrupted growth of $L$. monocytogenes under nonsterilized condition compared with that of L. monocytogenes alone at a refrigeration temperature [49]. The growth of L. monocytogenes in ham rice balls was higher than that in tuna rice balls, even under refrigeration. In general, the use of mayonnaise as a sauce reduced the estimated risk from L. monocytogenes. Tuna or ham rice balls mixed with gochujang had the highest value for the mean risk of illness (4.1 cases per hundred servings) regardless of temperature. Ranking of the other products was the same as for total illness, with LTM having the lowest mean risk of illness ( 3 cases per million servings) stored at $7^{\circ} \mathrm{C}$. However, this was still a much higher risk when compared with listeriosis caused by the consumption of cooked meat ( 0.000629 cases per million servings) and hotsmoked fish (0.000000989 cases per million servings), as reported by the EFSA [7]. These higher risks may have been due to the large serving size and intake frequency of rice balls in Korea. The total DALY per year, i.e., the annual health burden, of rice balls mixed with gochujang was 0.015 at all storage temperatures, which was the highest identified in this study. LHM exhibited the lowest total DALY (0.006) among ham rice balls. Hong, Kim, and Yoon [50] reported that the DALY of various hams contaminated with Campylobacter jejuni ranged from 0.000208 to 0.000346 . LTM exhibited the lowest total DALY among all tested rice balls. The susceptibility to listeriosis varies within different population groups; moreover, the risk of illness from consuming rice balls contaminated with $L$. monocytogenes is much 
TABLE 3: FDA-iRISK output: risk ranking of six rice balls stored at 7,15 , and $25^{\circ} \mathrm{C}$.

\begin{tabular}{lcccc}
\hline Code & Temperature $\left({ }^{\circ} \mathrm{C}\right)$ & Total illnesses ${ }^{2)}$ & Mean risk of illness ${ }^{3)}$ & Total DALY per year \\
\hline \multirow{2}{*}{ LTM $^{1)}$} & 7 & $0.0001 \mathrm{~b}$ & 0.000003 & 0.00000093 \\
& 15 & 0.075 & 0.003 & 0.001 \\
\hline \multirow{2}{*}{ LTS } & 25 & 0.0005 & 0.00002 & 0.004 \\
& 7 & 0.432 & 0.018 & 0.006 \\
\hline \multirow{2}{*}{ LTG } & 15 & 0.531 & 0.017 & 0.006 \\
& 25 & 0.404 & 0.041 & 0.015 \\
\hline \multirow{2}{*}{ LHM } & 7 & 0.978 & 0.041 & 0.015 \\
& 15 & 0.978 & 0.041 & 0.015 \\
\hline \multirow{2}{*}{ LHS } & 25 & 0.978 & 0.041 & 0.015 \\
& 15 & 0.978 & 0.035 & 0.012 \\
\hline \multirow{2}{*}{ LHG } & 25 & 0.831 & 0.016 & 0.006 \\
& 15 & 0.392 & 0.041 & 0.015 \\
& 25 & 0.978 & 0.033 & 0.012 \\
\hline
\end{tabular}

1) LTM, LTS, and LTG are tuna rice balls mixed with mayonnaise, soy sauce, and gochujang contaminated by L. monocytogenes; LHM, LHS, and LHG are ham rice balls mixed with mayonnaise, soy sauce, and gochujang contaminated by L. monocytogenes.2) Total illness is the total number of illnesses generated from the scenario. The total lifespan in the scenario is 70 years (duration of exposure). 3) Mean risk of illness represents the average probability of disease based on one serving.

higher in pregnant (0.20-20.76) and elderly groups (0.02-20.76; Supplementary Table 2) than in the general population.

\section{Conclusion}

In this study, the growth of L. monocytogenes in various rice balls was found to differ depending on the main food ingredients, such as tuna or ham, and sauces, such as mayonnaise, soy sauce, and gochujang. Additionally, the Baranyi model was identified as the optimal model to describe L. monocytogenes growth in rice balls and can be useful for conducting future risk assessment. The relative risk of illness from six rice balls was compared using FDA-iRISK based on the dose-response model, consumption, and DALY. Overall, ham rice balls presented a higher risk of listeriosis compared with tuna rice balls. L. monocytogenes in rice balls containing mayonnaise had the longest LT, possibly because of less favorable growth conditions such as low $\mathrm{pH}$ and the presence of lysozyme and ovotransferrin, which inhibit bacterial growth. Thus, rice balls containing mayonnaise exhibited a lower risk of illness than those containing soy sauce or gochujang. Because the intake of rice balls by Koreans is very high, the risk of listeriosis from rice balls is high. Thus, consistently managing food handling is necessary to control L. monocytogenes because it can grow even at low temperatures. These results may be useful in future studies evaluating the growth characteristics of L. monocytogenes in rice balls.

\section{Data Availability}

The data used to support the findings of this study are available from the corresponding author upon request.

\section{Conflicts of Interest}

The authors declare that there are no conflicts of interest regarding the publication of this paper.

\section{Supplementary Materials}

Supplementary Table 1: metrics of fit for models of $L$. monocytogenes growth in rice balls, fitted to experimental data $(n=4)$. Supplementary Table 2: risk ranking of six rice balls stored at 7,15 , and $25^{\circ} \mathrm{C}$ for susceptible population. (Supplementary Materials)

\section{References}

[1] J. Garbutt, Essentials of Food Microbiology, EdwardArnold, London, UK, 2nd edition, 1997.

[2] J. M. Jay, Modern Food Microbiology, Aspen Publishers, Inc., Gaithursburg, ML, USA, 6th edition, 2003.

[3] T. J. Montville and K. R. Matthews, Food Microbiology: An Introduction, ASM Press, Washington, DC, USA, 3rd edition, 2005.

[4] E. Scallan, R. M. Hoekstra, F. J. Angulo et al., "Foodborne illness acquired in the United States-major pathogens," Emerging Infectious Diseases, vol. 17, no. 1, pp. 7-15, 2011.

[5] WHO, "Risk assessment of listeria monocytogenes in readyto-eat foods," in Microbial Risk Assessment Series 5WHO, Geneva, Switzerland, 2004, http://www.fao.org/3/a-y5394e. pdf/.

[6] J. McLauchlin, R. T. Mitchell, W. J. Smerdon, and K. Jewell, "Listeria monocytogenes and listeriosis: a review of hazard characterisation for use in microbiological risk assessment of foods," International Journal of Food Microbiology, vol. 92, no. 1, pp. 15-33, 2004.

[7] EFSA (European Food Safety Authority), "Panel on Biological Hazards. Listeria monocytogenes contamination of ready-to- 
eat foods and the risk for human health in the EU," EFSA Journal, vol. 16, p. 5134, 2018.

[8] M. Pae, "Dietary habits and perception toward food additives according to the frequency of consumption of convenience food at convenience stores among university students in cheongju," Korean Journal of Community Nutrition, vol. 21, no. 2, pp. 140-151, 2016.

[9] S.-J. Kim, S. Y. Bu, and M.-K. Choi, "Preference and the frequency of processed food intake according to the type of residence of college students in Korea," Korean Journal of Community Nutrition, vol. 20, no. 3, pp. 188-196, 2015.

[10] Institute of Food Technologists, Evaluation and Definition of Potentially Hazardous Foods, Institute of Food Technologists, Chicago, IL, USA, 2001.

[11] Korea Food and Drug Administration, Korean Food Code, Seoul, South Korea, 2018, http://www.foodsafetykorea.go.kr/ portal/safefoodlife/food/foodRvlv/foodRvlv.do/.

[12] Y. M. Bae and S. Y. Lee, "Effect of microwave treatment and packaging methods on extending the shelf-life of RTE rice balls at room temperature," Korean Journal of Food Cookery Science, vol. 26, pp. 165-170, 2010.

[13] G.-J. Bahk, C.-H. Hong, D.-H. Oh, S.-D. Ha, K.-H. Park, and E. C. D. Todd, "Modeling the level of contamination of Staphylococcus aureus in ready-to-eat kimbab in Korea," Journal of Food Protection, vol. 69, no. 6, pp. 1340-1346, 2006.

[14] H. Lee, G. Lee, E. Yoon et al., "Computation of maximum edible time using monitoring data of Staphylococcus aureus in kimbap and food MicroModel," Food Hygiene and Safety Science, vol. 19, pp. 49-54, 2004.

[15] S. Miya, H. Takahashi, T. Ishikawa, T. Fujii, and B. Kimura, "Risk of Listeria monocytogenes contamination of raw readyto-eat seafood products available at retail outlets in Japan," Applied and Environmental Microbiology, vol. 76, no. 10, pp. 3383-3386, 2010.

[16] S.-H. Hong, N.-Y. Park, H.-J. Jo et al., "Risk ranking determination of combination of foodborne pathogens and livestock or livestock products," Journal of Food Hygiene and Safety, vol. 30, no. 1, pp. 1-12, 2015.

[17] C. H. Hong, W. C. Sim, S. J. Chun et al., "Predictive growth model of native isolated Listeria monocytogenes on raw pork as a function of temperature and time," Korean Journal Food Science Technology, vol. 37, pp. 850-855, 2005.

[18] M. Fakruddin, R. M. Mazumder, and K. S. B. Mannan, "Predictive microbiology: modeling microbial responses in food," Ceylon Journal of Science, vol. 40, pp. 121-131, 2011.

[19] A. Vermeulen, N. Smigic, A. Rajkovic et al., "Performance of a growth-no growth model for listeria monocytogenes developed for mayonnaise-based salads: influence of strain variability, food matrix, inoculation level, and presence of sorbic and benzoic acid," Journal of Food Protection, vol. 70, no. 9, pp. 2118-2126, 2007.

[20] CODEX 1998, Draft Principles and Guidelines for the Conduct of Microbiological Risk Assessment, Codex Committee on Food Hygiene. Report of the thirty-first session, Orlando, FL, USA, 1998.

[21] Y. Chen, S. B. Dennis, E. Hartnett et al., "FDA-iRISK-A comparative risk assessment system for evaluating and ranking food-hazard pairs: case studies on microbial hazards," Journal of Food Protection, vol. 76, no. 3, pp. 376-385, 2013.

[22] V. Capozzi, D. Fiocco, M. L. Amodio, A. Gallone, and G. Spano, "Bacterial stressors in minimally processed food," International Journal of Molecular Sciences, vol. 10, no. 7, pp. 3076-3105, 2009.
[23] I. Lebert, V. Robles-Olvera, and A. Lebert, "Application of polynomial models to predict growth of mixed cultures of Pseudomonas spp. and Listeria in meat," International Journal of Food Microbiology, vol. 61, no. 1, pp. 27-39, 2000.

[24] H. J. Moon, J. G. Lim, and K. S. Yoon, "Comparative study of change in Salmonella enteritidis and Salmonella typhimurium populations in egg white and yolk," Journal of Food Hygiene and Safety, vol. 31, no. 5, pp. 342-348, 2016.

[25] R. B. Smittle, "Microbiological safety of mayonnaise, salad dressings, and sauces produced in the United States: a review," Journal of Food Protection, vol. 63, no. 8, pp. 1144-1153, 2000.

[26] F. Baty and M.-L. Delignette-Muller, "Estimating the bacterial lag time: which model, which precision?" International Journal of Food Microbiology, vol. 91, no. 3, pp. 261-277, 2004.

[27] K. Ye, H. Wang, X. Zhang, Y. Jiang, X. Xu, and G. Zhou, "Development and validation of a molecular predictive model to describe the growth of listeria monocytogenes in vacuumpackaged chilled pork," Food Control, vol. 32, no. 1, pp. 246-254, 2013.

[28] M.-L. Pla, S. Oltra, M.-D. Esteban, S. Andreu, and A. Palop, "Comparison of primary models to predict microbial growth by the plate count and absorbance methods," BioMedical Research International, vol. 2015, pp. 1-14, 2015.

[29] R. L. Buchanan, R. C. Whiting, and W. C. Damert, "When is simple good enough: a comparison of the gompertz, baranyi, and three-phase linear models for fitting bacterial growth curves," Food Microbiology, vol. 14, no. 4, pp. 313-326, 1997.

[30] M. Y. Li, X. M. Sun, G. M. Zhao et al., "Comparison of mathematical models of lactic acid bacteria growth in vacuum-packaged raw beef stored at different temperatures," Journal of Food Science, vol. 78, no. 4, pp. M600-M604, 2013.

[31] M. Li, H. Niu, G. Zhao et al., "Analysis of mathematical models of Pseudomonas spp. growth in pallet-package pork stored at different temperatures," Meat Science, vol. 93, no. 4, pp. 855-864, 2013.

[32] V. Zuliani, I. Lebert, J.-C. Augustin, P. Garry, J.-L. Vendeuvre, and A. Lebert, "Modelling the behaviour of Listeria monocytogenes in ground pork as a function of $\mathrm{pH}$, water activity, nature and concentration of organic acid salts," Journal of Applied Microbiology, vol. 103, no. 3, pp. 536-550, 2007.

[33] A. S. Sant'Ana, M. Landgraf, M. T. Destro, and B. D. G. M. Franco, "Prevalence and counts of Salmonella spp. in minimally processed vegetables in Sao Paulo, Brazil," Food Microbiol, vol. 28, pp. 1235-1237, 2011.

[34] K. Luo, S.-S. Hong, J. Wang et al., "Development of predictive models for the growth kinetics of Listeria monocytogenes on fresh pork under different storage temperatures," Journal of Food Protection, vol. 78, no. 5, pp. 921-926, 2015.

[35] K. M. Sorrells, D. C. Enigl, and J. R. Hatfield, "Effect of pH, acidulant, time, and temperature on the growth and survival of Listeria monocytogenes," Journal of Food Protection, vol. 52, no. 8, pp. 571-573, 1989.

[36] F. Devlieghere, A. H. Geeraerd, K. J. Versyck, B. Vandewaetere, J. Van Impe, and J. Debevere, "Growth of Listeria monocytogenes in modified atmosphere packed cooked meat products: a predictive model," Food Microbiology, vol. 18, no. 1, pp. 53-66, 2001.

[37] E. Franz, S. O. Tromp, H. Rijgersberg, and H. J. Van Der FelsKlerx, "Quantitative microbial risk assessment for Escherichia coli O157:H7, Salmonella, and Listeria monocytogenes in leafy green vegetables consumed at salad bars," Journal of Food Protection, vol. 73, no. 2, pp. 274-285, 2010.

[38] S. Tienungoon, D. A. Ratkowsky, T. A. Mcmeekin, and T. Ross, "Growth limits of listeria monocytogenesas a 
function of temperature, $\mathrm{pH}, \mathrm{NaCl}$, and lactic acid," Applied and Environmental Microbiology, vol. 66, no. 11, pp. 49794987, 2000.

[39] T. Ding, S. M. E. Rahman, and D.-H. Oh, "Inhibitory effects of low concentration electrolyzed water and other sanitizers against foodborne pathogens on oyster mushroom," Food Control, vol. 22, no. 2, pp. 318-322, 2011.

[40] L. Huang, "Growth Kinetics of Escherichia coli O157:H7 in mechanically-tenderized beef," International Journal of Food Microbiology, vol. 140, no. 1, pp. 40-48, 2010.

[41] K. M. Cho, D. M. Kambiranda, and S. W. Kim, "Simultaneous detection of food-borne pathogenic bacteria in ready-to-eat kimbab using multiplex PCR method," Food Science. Biotechnology, vol. 17, pp. 1240-1245, 2008.

[42] G.-N. Shin, Y.-R. Kim, and M.-H. Kim, "Nutritional evaluation of convenience meals in convenience stores near the universities," Korean Journal of Community Nutrition, vol. 22, no. 5, pp. 375-386, 2017.

[43] R. Pouillot, K. Hoelzer, Y. Chen, and S. B. Dennis, "Listeria monocytogenesDose response revisited-incorporating adjustments for variability in strain virulence and host susceptibility," Risk Analysis, vol. 35, no. 1, pp. 90-108, 2015.

[44] C. M. Noordhout, B. Devleesschauwer, F. Angulo et al., "The global burden of listeriosis: a systematic review and metaanalysis," The Lancet Infectious Diseases, vol. 14, pp. 10731082, 2014.

[45] Korea centers for disease control and prevention. Korea health statistics 2016: korea national health and nutrition examination survey (KNHANES VII-1). http://knhanes.cdc. go.kr/.

[46] A. H. Havelaar, J. A. Haagsma, M.-J. J. Mangen et al., "Disease burden of foodborne pathogens in The Netherlands, 2009," International Journal of Food Microbiology, vol. 156, no. 3, pp. 231-238, 2012.

[47] J. M. Kemmeren, M.-J. J. Mangen, Y. T. H. P. Van Duynhoven, and A. H. Havelaar, "Priority Setting Of Foodborne Pathogens-Disease Burden And Costs Of Selected Enteric Pathogens," Rijksinstituut voor Volksgezondheid en Milieu (RIVM), Veinna, Austria, 2006.

[48] C. M. Noordhout, B. Devleesschauwer, F. Angulo et al., "The global burden of listeriosis: a systematic review and metaanalysis," The Lancet, vol. 14, pp. 1073-1082, 2014.

[49] Y. J. Lee, B. S. Jung, H. J. Yoon, K.-T. Kim, H.-D. Paik, and J.-Y. Lee, "Predictive model for the growth kinetics of Listeria monocytogenes in raw pork meat as a function of temperature," Food Control, vol. 44, pp. 16-21, 2014.

[50] S. Hong, H. Kim, and K. Yoon, "Survival and risk comparison of Campylobacter jejuni on various processed meat products," International Journal of Environmental Research and Public Health, vol. 13, no. 6, p. 580, 2016. 